\title{
TALE 2014
}

\section{Teaching, Assessment, and Learning for Engineering Conference}

\author{
8-10 December 2014 Wellington, New Zealand
}

\section{CALL FOR PAPERS Draft Paper deadline: 11 August 2014}

This year TALE will be co-located with:

\section{AAEE- AUSTRALIAN ASSOCIATION OF ENGINEERING EDUCATION CONFERENCE 2014}

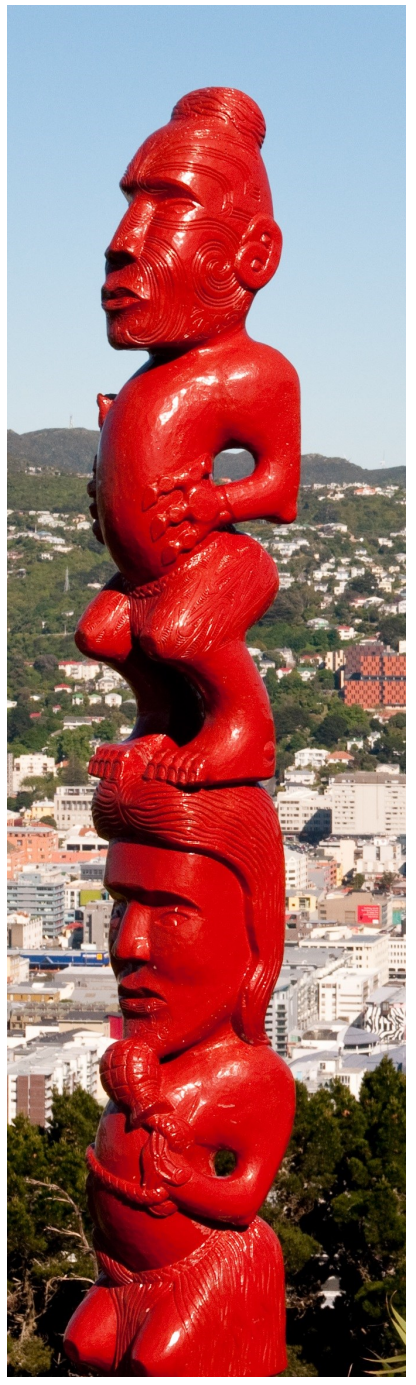

\section{Overview}

The aim of TALE is to provide a forum for academicians and professionals from various educational fields and with cross-disciplinary interests to network, share knowledge and engage in dialogue around the theme of fostering innovation and excellence in engineering education. To this end, both research and practice-oriented papers are invited that encompass all aspects of education in the engineering fields (including computing, computer science, information technology and cognate disciplines). The conference features traditional paper presentations, workshops, as well as keynotes by renowned educational ex-

\section{Paper Categories}

TALE welcomes full papers up to eight-pages and work-in-progress papers up to four-pages that address the broad tracks of (1) innovative practice, (2) research-to-practice, and (3) research. Work-in-progress papers are typically in areas where it is understood the work is in an early or intermediate stage and authors are seeking feedback from the community. Additional information may be found on the TALE 2014 Web site.

www.tale-conference.org

\section{Presentation Formats}

Proposals for participation in TALE 2014 can be submitted in the following formats:

- Papers: full paper

- $\quad$ Papers: work-in-progress (WIP)

- Special sessions

- Panels

- Workshops

Each of these formats is described in detail on the conference website.

\section{Schedule}

Draft Papers due:

\section{$\Rightarrow \quad 11$ August 2014}

Notification of paper acceptance:

$\Rightarrow \quad 29$ September 2014

Final paper submission:

$\Rightarrow \quad 27$ October 2014
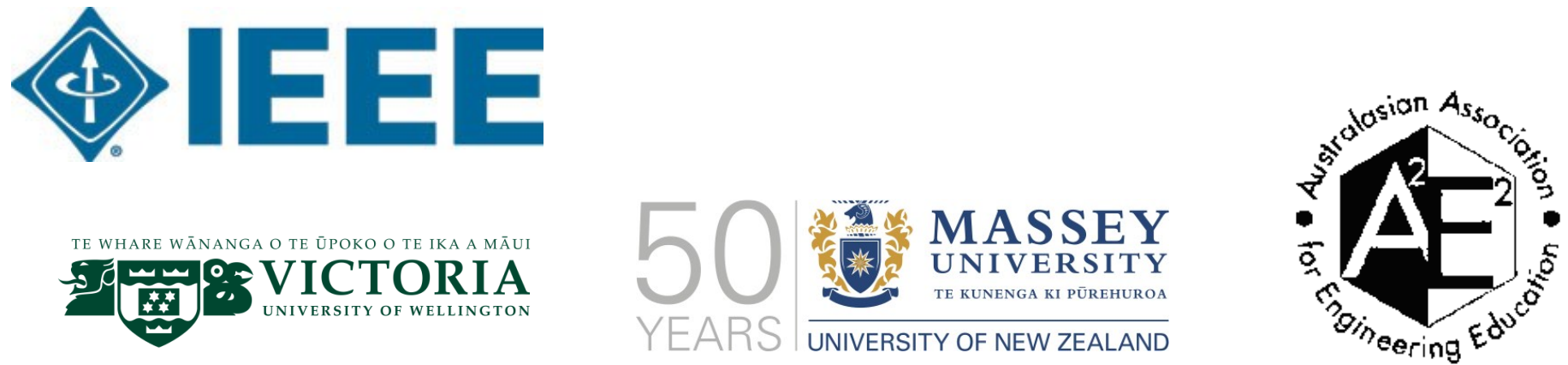